\title{
Incorporación de la ISO 26000, sobre organizaciones empresariales, en la legislación colombiana
}

\author{
Incorporating the ISO 26000, on business organizations, \\ in the Colombian law
}

Incorporação da ISO 26000, sobre organizações empresariais, na legislação colombiana.

Recibido el 28 de septiembre de 2015. Aceptado el 28 de noviembre de 2015

\author{
Juan Pablo Martínez Arango* \\ Colombia \\ León Sigifredo Ciro Ríos** \\ Colombia
}

\section{Resumen}

Objetivo: determinar el nivel de incorporación de la

Para citar este artículo:

Martínez Arango, Juan Pablo

y Ciro Ríos, León Sigifredo (diciembre, 2015). Incorporación de la ISO 26000, sobre organizaciones empresariales, en la legislación colombiana. Ánfora, 22(39), 147-1678 Universidad Autónoma de Manizales. ISSN 0121-6538. norma ISO 26000 en las organizaciones empresariales, según las leyes colombianas. Metodología: se realizó un análisis documental a cerca de 8.000 leyes colombianas relacionadas con cuatro categorías: Organizacional, Social, Ambiental y Operacional, las cuales se derivaron de los siete temas y 38 subtemas que componen la Norma Guía ISO 26000 de Responsabilidad Social. El alcance descriptivo de la realidad legislativa colombiana, focalizada en las cuatro categorías de análisis mencionadas, fue posible tras el diligenciamiento de una matriz en la cual se condensan los hallazgos de esta investigación. Resultados: se estableció un nivel del

\footnotetext{
* Magíster en Administración de Negocios. Profesor Universidad Autónoma de Manizales. Correo electrónico: juanmartinezarango@hotmail.com

** Doctor en Humanidades y Ciencias Sociales. Profesor Universidad Autónoma de Manizales. Correo: lesiciro@autonoma.edu.co
} 
58\% de incorporación de las organizaciones empresariales privadas. El estudio también evidenció un componente diferenciador de las organizaciones empresariales de capital público, las Ilamadas Empresas Industriales y Comerciales del Estado -EICE's-, ya que en ellas se halló un nivel de incorporación del 83\%. Conclusiones: la diferencia entre los dos tipos de organizaciones (empresariales privadas y empresariales de capital público) radica en que en las EICE's es obligatoria la rendición pública de cuentas y todos los demás elementos de la categoría Organizacional, lo que no pasa en las privadas. También se concluye que en ambos tipos de empresas los aspectos ambientales, de derechos laborales y derechos de los consumidores están incorporados en su totalidad.

Palabras Clave: Responsabilidad Social Empresarial, Norma ISO 26000, Legislación Colombiana, Organizaciones empresariales.

\section{Abstract}

Objective: to determine the level of incorporation of the ISO 26000 standard in business organizations, according to the Colombian law. Methodology: a documentary analysis was done with approximately 8,000 Colombian laws related to four categories: Organizational, Social, Environmental and Operational, which were derived from the seven topics and 38 subtopics that comprise the Standard ISO 26000 on Social Responsibility. The descriptive scope of the Colombian legislative reality, focused on the four categories of the aforementioned analysis was possible after filling out a matrix in which the findings of this research are condensed. Results: a level of $58 \%$ incorporation of private business organizations was established. The study also showed a distinctive component of the business organizations of public capital, called the State Industrial and Commercial Companies -EICE's-, since in them a level of incorporation of 83\% was found. Conclusions: the difference between the two types of organizations (private business and publicly owned business) is that in EICE's public accountability and all other elements of the organizational category are mandatory, which does not happen in private business. In both types of companies the environmental, labor rights and consumer rights are incorporated in full.

Keywords: Corporate Social Responsibility, ISO 26000, Colombian Legislation, Business Organizations. 


\section{Resumo}

Objetivo: determinar o nível de incorporação da norma ISO 26000 nas organizações empresariais, segundo as leis colombianas. Metodologia: realizou-se uma analise documental de aproximadamente 8.000 leis colombianas relacionadas com quatro categorias: Organizacional, Social, Ambiental e Operacional, as quais se derivaram dos sete temas e 38 subtemas que compõem a Norma Guia ISO 26000 de Responsabilidade Social. $\bigcirc$ alcance descritivo da realidade legislativa colombiana, focada nas quatro categorias de analise mencionadas, foi possível depois do tramite de uma matriz na qual se condensam os achados de esta pesquisa. Resultados: estabeleceu-se um nível de 58\% de incorporação das organizações empresariais privadas. $\bigcirc$ estudo também evidenciou um componente diferenciador das organizações empresariais de capital público, as chamadas Empresas Industriais e Comerciais do Estado-EICE's-, já que em elas se achou um nível de incorporação de 83\%. Conclusões: a diferença entre os dois tipos de organizações (empresariais privadas e empresariais de capital público) radica em que nas EICE's é obrigatória a rendição pública de contas e todos os demais elementos da categoria Organizacional, o que não acontece nas privadas. Também se conclui que nos dois tipos de empresas os aspectos ambientais, de direitos laborais e direitos dos consumidores estão incorporados por completo.

Palavras Chave: Responsabilidade Social Empresarial, Norma ISO 26000, Legislação Colombiana, Organizações empresariais. 


\section{Introducción}

Esta investigación describe la relación del marco legal colombiano vigente para las organizaciones empresariales y la Responsabilidad Social Empresarial, RSE, según se establece en la norma guía ISO 26000 (dedicada a la Responsabilidad Social). Cuando se habla de organizaciones empresariales, se debe tener en cuenta que la empresa tiene en su estructura un conjunto de elementos que permiten definirla como organización, a saber: a) Un grupo de personas asociadas; b) El logro de un fin común; c) Que establecen entre ellas, a tal fin, relaciones formalizadas; d) Con pretensión de continuidad en el tiempo, y e) Con posibilidad de sustituir a sus propios miembros sin que peligre la supervivencia de la organización (Infestas, 2001). El carácter de organización que tienen las empresas también se relaciona con el hecho de estar reguladas dentro de la sociedad por un conjunto de normas -empezando por las que le dan vida jurídica- y por la capacidad de ser sujetos de derechos y obligaciones dentro de la sociedad. Adicionalmente, es importante tener en cuenta el contexto donde estas empresas desarrollan sus actividades; este contexto es el mismo Estado, porque este tiene un marco regulatorio amplio que comienza con la Constitución Política y termina con regulaciones específicas para cada actividad productiva.

Todas las organizaciones empresariales en Colombia tienen obligaciones sociales y colectivas; en su objeto social, además de buscar el lucro, se incluye el deber de seguir lineamientos sociales y ambientales. De hecho, en el marco del Estado Social de Derecho se defiende la aplicación de los derechos consagrados en la Constitución Colombiana, y de los principios y valores que lo constituyen. Es aquí, donde existe una convergencia entre estos principios y valores de los Estados sociales de derecho y la RSE; esta integración de la RSE en las políticas empresariales está cambiando la propia definición de lo que es una empresa, porque no sólo es una organización que busca el mayor beneficio económico, sino que también debe alcanzar propósitos sociales y ambientales; es decir, debe responder por otros aspectos inherentes al contexto social donde desarrolla su actividad (Baylos, 2013). En este punto el derecho y la RSE se complementan, porque esta última puede llenar ciertos vacíos que existen en los marcos jurídicos de las organizaciones empresariales. A este conjunto de normas jurídicas que algunos identifican con el "Derecho", es a lo que se le denomina normas duras (Hard Law), por su obligatoriedad, independientemente de la posición de las personas; es decir, todos deben cumplirlas aunque no estén de acuerdo con ellas. En contraposición, existe otro tipo de normas que son voluntarias, es decir, las personas son las que deciden implementarlas o no, pero una vez toman la decisión de hacerlo, se convierten en obligatorias para ellos; este tipo de normas son las llamadas normas blandas (Soft Law). Un ejemplo de ellas, son las normas de certificación en sistemas 
de gestión o guías como la ISO 26000. Sobre este tema son muy relevantes los conceptos planteados por la noruega María Gjølberg (2011) en su texto Explaining Regulatory Preferences: CSR, SoftLaw, or HardLaw? Insights from Survey of Nordic Pioneers in CSR. La autora plantea que, en general, hay un conocimiento muy limitado acerca de la RSE, sobre cómo las normas duras y las normas blandas pueden unirse y, por ello, no hay consenso en cómo la RSE puede ser afectada de manera negativa o positiva, es decir, si se crean normas duras para fomentar la RSE y, viceversa, si la RSE puede tener efectos en la creación de normas duras.

Ahora bien, en la perspectiva jurídica el marco normativo colombiano de manera general es muy extenso, incluso si sólo se tienen en cuenta las normas vigentes para las organizaciones empresariales. Pero si se las compara con los principios y temas que contiene la ISO 26000, se encuentra que están cobijadas por normas duras sobre derechos humanos, derechos de los trabajadores, derechos al medio ambiente, etcétera; no obstante se desconoce cuál es el grado de correlación entre estos dos marcos normativos ${ }^{1}$, lo cual da origen al interrogante en cuya respuesta se centró la investigación que origina este artículoº ¿cuál es el nivel de incorporación de los principios y temas ISO 26000 en la legislación colombiana vigente para las organizaciones empresariales de bienes y servicios? La investigación de la que se deriva este trabajo buscó establecer el nivel de incorporación de los principios y temas de la norma guía ISO 26000 en la legislación colombiana vigente para las organizaciones empresariales de bienes y servicios, temas y principios agrupados en cuatro categorías: organizacional, social, ambiental y operacional. Estas categorías focalizaron la búsqueda y sistematización de la información que se presenta en el apartado de "resultados" de este artículo.

En Colombia hay antecedentes investigativos sobre la implementación de criterios de RSE en empresas nacionales. En los que guardan relación con esta investigación se resalta el trabajo de la Universidad Nacional "Responsabilidad Social Empresarial: Una reflexión desde la gestión, lo social y ambiental”; el de la Universidad Javeriana "Capitalismo y Empresa: Reflexiones desde la ética y la RSE"; el de la Universidad Santiago de Cali, "RESPONSABILIDAD SOCIAL EMPRESARIAL: Su origen, evolución y desarrollo en Colombia”, y otro de la Universidad Externado

\footnotetext{
1. El marco normativo duro comprendido por el bloque de constitucionalidad, leyes, decretos, etc., y el marco normativo blando contenido en la ISO 26000.

2. Como podrá apreciarse, muchas de las leyes sometidas a examen son anteriores al año 2010 , año en que se expidió la ISO 2600. Ello indica que la legislación no se produjo con la intención (explícita o implícita) de incorporar la ISO 26000 en las leyes colombianas. Significa que es necesario contar con un estudio que determine qué tan voluntaria u obligada es la ISO 26000 en Colombia.
} 
de Colombia llamado "Responsabilidad social empresarial: Fundamentos y aplicación en las organizaciones de hoy”, entre otros. En el 2010, en la Universidad Autónoma de Manizales se publicó un trabajo que guarda una mayor relación con el objeto del presente estudio, "La Responsabilidad Social Empresarial vista a la luz de los intentos normativos" (Ciro, 2010). En éste, se hace una descripción de algunas de las normas blandas relacionadas con la RSE, v. gr., la SA (Social Accountability) 8000 de $1997^{3}$ (que hace énfasis en la administración de los procesos internos de las organizaciones empresariales) el Libro Verde de la Unión Europea de $2001^{4}$, y la ISO 26000 del 2010.

En el ámbito internacional, Kenneth M. Amaeshi y Bongo Adi (2007), publicaron un documento titulado "Reconstructing the corporate social responsibility construct in utlish", en "Businesss Ethics: An European Review en 2007, en cuyas conclusiones sobre la discusión respecto a los conceptos relacionados con Responsabilidad Social Corporativa, RSC, establecen que se deben fortalecer los gobiernos y endurecer las normas regulatorias para controlar a las organizaciones empresariales. Por su parte, Archie B. Carroll (2001) plantea en su texto "The pyramid of corporate Social Responsability: Toward the moral managment of organizational stakeholders", que la RSE tiene varios componentes: el económico, el ético, el filantrópico y el legal, es decir, no separa ni pone lo legal como una base, puesto que lo incluye dentro del concepto, y aduce que constituye un componente más de ella misma. Otro documento de investigación revisado fue el realizado por los profesores Isabelle Tricot-Chamard y Christopher Estay (2011) de la BEM Bordeaux Management School de Francia, quienes escribieron en el 2011 un texto titulado Quand la responsabilité juridique vient en richir la responsabilité sociale des entreprises. En este documento, argumentan que la RSE puede contribuir como una extensión del principio de precaución del cuidado del medio ambiente que está establecido, en este caso, en la Constitución de Francia. Es decir, se complementan de tal forma que la RSE termina siendo aliada de las empresas al llevarlas a evitar daños y perjuicios, que dado el caso que sucedieran, deberían ser resarcidos dentro del contexto de la responsabilidad jurídica.

La revisión de antecedentes investigativos sobre la relación normas duras normas blandas se inserta en el contexto teórico de la Bussines Ethics. Hay una

\footnotetext{
3. La SA 8000 si es una norma certificable, lo que implica que es voluntaria, pero una vez se ha decido implementarla es obligatoria para poder mantener la certificación. Esta norma regula fundamentalmente las prácticas laborales, especialmente el cumplimiento de los acuerdos de la OIT (Organización Internacional del Trabajo) así como también el cumplimiento de las leyes laborales nacionales (Ciro, 2010).

4. El Libro Verde de la EU es una propuesta marco reactiva en respuesta de la presión de los consumidores para prevenir nuevos escándalos de corrupción en que han incurrido empresas globalizadas (Ciro, 2010).
} 
fuerte tendencia a disociar la responsabilidad social del marco legal, con lo cual la RSE se adoptaría de manera voluntaria, como proponen los lineamientos normativos conexos con el enfoque RS que defiende la ISO 26000 (Ciro, 2010). Que la RS tenga impacto en el entramado legislativo de un país es una postura cercana a quienes defienden la necesidad de una intervención moderada del Estado en el mercado, postura que defienden los coautores de este trabajo. En Colombia, como se concluye de este trabajo, hay materias de la RS que son de implementación obligatoria, convencional y materias de la RS que son voluntarias, posconvencionales (Carracedo, 1989; Lozano, 1999). Esa situación guarda relación con el hecho de que Colombia se ha definido en su Constitución política como un Estado Social de Derecho. Habrá que realizar una investigación posterior sobre textos constitucionales de otros países en los que se consagre el Estado Social de Derecho para determinar si es posible o no generalizar la relación entre Responsabilidad social empresarial y Estado Social de Derecho.

\section{Metodología}

Para responder el interrogante que orientó la investigación, se realizó, primero, la recopilación de las leyes colombianas vigentes para las organizaciones empresariales de bienes y servicios que pudieran relacionarse con la norma guía ISO 26000. Después, se estableció la relación entre los principios y temas de la norma ISO 26000 y las leyes vigentes aplicables para las empresas en Colombia, mediante la construcción de una matriz donde se relacionaron las leyes y los aspectos contenidos en la norma ISO. Posteriormente, se estableció el nivel de incorporación de los principios y subtemas de esta norma guía ISO 26000 en cada una de las leyes incluidas en la matriz donde se relacionaron estas mismas con los aspectos contenidos en esa norma ISO. Por último, se identificaron vacíos en la legislación colombiana en materia de RSE y en referencia a la ISO 26000, así como los obstáculos y potenciales en la incorporación de la RSE en Colombia en referencia al marco normativo duro.

Mediante este procedimiento se logró una descripción de cómo es el marco legal colombiano y se realizó una compilación de todas las leyes actualmente vigentes expedidas desde 1886, que guardan relación directa con cada uno de los cuatro grupos o categorías de los temas que contiene la ISO 26000. Como se observa, el carácter de esta investigación fue descriptivo. La descripción se realizó mediante un procedimiento de análisis documental de la legislación colombiana en el nivel de ley, rastreable en tres portales jurídicos públicos, con corte a julio de 2014. La técnica empleada, en síntesis, fue la revisión documental, 
buscando con ello dotar de contenido empírico a las cuatro categorías en que se operacionalizó la Norma Guía ISO 26000. Todo el análisis se plasmó en un instrumento tipo matriz, con base en la cual se aplicó la escala de medición que más adelante se describe.

\section{Categorias:}

En el referente teórico se agruparon los siete temas que componen la norma guía ISO, en cuatro categorías por su afinidad conceptual, a saber:

- Organizacional: gobernanza de la organización.

- Social: derechos humanos, prácticas laborales y participación activa y desarrollo de la comunidad.

- Ambiental: medio ambiente.

- Operacional: prácticas justas de operación y los asuntos de los consumidores

Con base en la anterior categorización, se realizó un levantamiento de las leyes vigentes existentes en el ordenamiento jurídico colombiano; por lo tanto, la unidad de trabajo estuvo constituida las leyes vigentes que tengan pertinencia con las organizaciones empresariales de bienes y servicios dentro de todo el marco normativo colombiano (se excluyeron aquellas leyes que no tienen relación o vínculo alguno con las organizaciones empresariales de bienes y servicios, por ejemplo, leyes que otorgan condecoraciones, o de ascensos, o de nombramientos, o de cambios en la estructura organizacional del Estado colombiano).

Cada una de estas leyes se relacionó con algún tema existente en una de las cuatro categorías en que se clasificaron estos temas que contienen la ISO 26000 (unidad de análisis) o incluso con varios de ellos, cuando ese fue el caso. Posteriormente, a las leyes relacionadas con alguna de las cuatro categorías, se hizo un análisis de cada tema usando la matriz (instrumento) donde se plasmó el objeto y una breve descripción de cada una ellas; subsiguientemente, haciendo una operación matemática simple de división (al ser cuatro categorías, a cada categoría se le asignó la cuarta parte del total, es decir el 25\%, y este 25\% se dividió por el número de temas existente en esa categoría) se le asignó un valor expresado en porcentaje. Por ejemplo, a la primera categoría que es la operacional se le asignó un total de 25\%, como esta sólo tiene dos temas (Planeación estratégica y rendición de cuentas) a cada una de ellas se les asignó un valor máximo de 12,5\%, así se ponderó el grado de incorporación de estas leyes en los principios y temas de la norma guía ISO 26000. 
Como ya se mencionó, el análisis partió de decantar cada uno de los 38 aspectos que contiene la norma guía ISO 26000 en la matriz, divididos en cuatro categorías y a cada una de ellas asignarle un porcentaje del $25 \%$, y al interior de cada categoría dividir ese $25 \%$ por el número de aspectos/temas que contenía:

Tabla 1. Subtemas en las Categorías.

\begin{tabular}{|c|c|c|c|}
\hline Categoría & $\begin{array}{c}\text { Subtemas } \\
\text { en cada } \\
\text { categoría }\end{array}$ & $\begin{array}{c}\text { Porcentaje } \\
\text { máximo } \\
\text { por cada } \\
\text { subtema }\end{array}$ & $\begin{array}{c}\text { Porcentaje } \\
\text { total } \\
\text { para cada } \\
\text { categoría }\end{array}$ \\
\hline Organizacional: gobernanza de la organización. & 2 & $12,5 \%$ & $25 \%$ \\
\hline $\begin{array}{c}\text { Social: derechos humanos, prácticas laborales } \\
\text { y participación activa y desarrollo de la } \\
\text { comunidad. }\end{array}$ & 20 & $1,25 \%$ & $25 \%$ \\
\hline $\begin{array}{c}\text { Ambiental: medio ambiente. } \\
\begin{array}{c}\text { Operacional: prácticas justas de operación y los } \\
\text { asuntos de los consumidores. }\end{array}\end{array}$ & 12 & $2,084 \%$ & $25 \%$ \\
\hline Total & 38 & $100 \%$ & $100 \%$ \\
\hline
\end{tabular}

Fuente: elaboración propia

Luego de construir la matriz, se revisaron los portales gubernamentales donde están las bases de datos que contienen las leyes expedidas en Colombia desde $1886^{5}$, y con la información obtenida se hizo el compendio de las leyes que guardaban alguna relación con los 38 subtemas contenidos en la ISO 26000. Con estas leyes se realizó la ponderación para obtener el nivel de incorporación de los principios y temas de la norma guía ISO 26000 en cada una de las leyes incluidas en esta matriz.

Si el porcentaje agregado de incorporación de la norma osciló entre 91 y $100 \%$, el nivel asignado fue de superior; entre 80 y 90, alto; entre 60 y 79, medio, e inferior a 60 , bajo.

\footnotetext{
5. A) El portal de la Secretaría del Senado que contiene todas las leyes promulgadas desde la entrada en vigencia de la Constitución de 1991, es decir, desde el 1 de enero de 1992 (Desde esa fecha comenzó la numeración, y hoy día se ha llegado a la Ley 1734). B) El portal de la Cámara de Representantes donde se encuentran especialmente todas las leyes de antes del 1 de enero de 1992. C) El nuevo portal estatal "SUIN" , que es el Sistema Único de Información Normativa del Estado Colombiano, y que tiene como finalidad permitir la consulta vía internet de las leyes y decretos (de carácter general) expedidos desde 1886.
} 


\section{Resultados}

Los resultados se presentan de acuerdo con cada una de las cuatro categorías en que se organizaron los temas contenidos en la norma ISO 26000.

Ponderación Categoría Organizacional: en Colombia no existen leyes que obliguen a las organizaciones empresariales privadas a realizar algún tipo de planeación ni a hacer rendición de cuentas de manera pública; sólo si están creadas como sociedades, tienen la obligación de rendir un Informe ante los propietarios por la gestión realizada por sus gerentes o directivos cada año (Ley 603 de 2000), y deben depositar una copia de los estados financieros en la Cámara de Comercio de su domicilio, donde deben estar inscritas (Ley 222 de 1995). No sucede lo mismo para las organizaciones empresariales de capital público, como las Empresas Industriales y Comerciales del Estado (EICE's), que a pesar de que son reguladas por el derecho privado en su funcionamiento y contratación, deben acatar las normas de derecho público en torno a planeación, control interno y rendición de cuentas ante la comunidad, de manera pública. Lo mismo sucede con las Empresas de Servicios Públicos (ESP's), las cuales tienen en la Ley 142 de 1994 su marco jurídico. Este tipo de empresas que forman parte de la estructura del Estado, pero que compiten con otras empresas privadas, deben cumplir con los lineamientos de las Leyes 87 de 1993 (Control interno), 872 de 2003 (Gestión de Calidad), 489 de 1998 (Participación y democratización de la gestión), 222 de 1995 y 603 de 2000 (si es una sociedad), y la 951 de 2005 que ordena hacer actas de informes de gestión en todas las entidades, ya sean estas públicas o privadas, o si manejan fondos o bienes del Estado.

Por lo anterior, lo que evidenció el análisis de esta categoría es que en relación con las empresas privadas, el resultado es cero por ciento $(0 \%)$ de un máximo de 25 puntos porcentuales (25\%), pero en el caso de que la evaluada sea una empresa pública que funcione y contrate bajo un marco legal privado (como las EICE's y ESP's). Esta ponderación será por el máximo valor asignado para esta categoría, que es del veinticinco por ciento (25\%), tal como se puede ver en el siguiente cuadro: 
Tabla 2. Matriz Parcial Categoría Organizacional.

\begin{tabular}{|c|c|c|}
\hline $\begin{array}{c}\text { Categoría Organizacional: Gobernanza de la } \\
\text { Organización }\end{array}$ & $\begin{array}{c}\text { Subtemas } \\
\text { incorporados } \\
\text { en la legislación } \\
\text { colombiana }\end{array}$ & $\begin{array}{c}\text { Porcentaje } \\
\text { Asignado a } \\
\text { cada subtema }\end{array}$ \\
\hline Caso Organizaciones Empresariales con capital privado & No & $0 \%$ \\
\hline TOTAL CATEGORÍA & Privadas & $0 \%$ \\
\hline $\begin{array}{c}\text { Caso Organizaciones Empresariales con capital público } \\
\text { con marco legal privado para funcionar y contratar } \\
\text { (EICE's Y EPS's) }\end{array}$ & Si & $12,5 \%$ \\
\hline TOTAL CATEGORÍA & Públicas* & $25 \%$ \\
\hline \multicolumn{2}{|c|}{} \\
\hline
\end{tabular}

Fuente: elaboración propia

Ponderación Categoría Social: algunos de los 20 subtemas de esta categoría se encuentran completamente incorporados en la legislación colombiana. Tal es el caso, por ejemplo, en asuntos de protección de grupos vulnerables (mujeres, niños, minorías étnicas y discapacitados), en la lucha en contra de la discriminación y el trato desigual (por raza, género, condición social, edad, o discapacidad), discriminaciones que hoy son incluso calificadas como delitos (Ley 1482 de 201 1), en la protección de los trabajadores, en el respeto de los principios y derechos fundamentales en el trabajo, en el reconocimiento del marco legal de las relaciones laborales, de las condiciones de trabajo, de la protección social, de la salud y seguridad ocupacional, y del diálogo social (se resalta la existencia de una comisión permanente de concertación de políticas salariales y laborales ley 278 de 1996), muchas de ellas originadas en la ratificación de acuerdos de la Organización Internacional del Trabajo - OIT.

Lo mismo sucede con los subtemas de los derechos civiles, políticos, sociales, económicos y culturales, resaltando que desde la misma Constitución Política de Colombia se encuentran protegidos. Incluso, hay mecanismos para su defensa como lo son la acción de tutela, cuando el derecho es individual o tiene conexidad con alguno de los denominados derechos fundamentales y las acciones populares y de grupo, cuando son derechos grupales o colectivos. Es de resaltar que Colombia suscribió y ratificó -mediante la Ley 74 de 1968 el Pacto Internacional de Derechos Económicos, Sociales y Culturales en el Marco de las Naciones Unidas, y mediante la Ley 16 de 1972- la Convención Americana sobre Derechos Humanos, llamado "Pacto de San José de Costa Rica”, que incluye la protección de estos derechos. No sucede lo mismo con los demás subtemas, que aunque en algunos casos exista alguna ley que los cubra parcialmente, como 
sucede en el subtema de las situaciones de riesgo (se identificó una ley que tiene un fin específico de proteger un grupo de personas que trabajan en labores periodísticas y los defensores de derechos humanos); no se consideró que están completamente incorporados en la legislación colombiana y por ello se les asignó un cero por ciento $(0 \%)$.

El resultado final en esta segunda categoría para todo tipo de organización empresarial, es de un $10 \%$ de un total de $25 \%$, destacando que la obligación de la formación, la educación de los trabajadores, el acceso a la tecnología, la creación de empleo, la salud y la inversión social, sigue siendo del gobierno, quien mediante sus políticas y planes de desarrollo, está asumiendo casi toda la carga en estos aspectos. Tal como se puede observar en el siguiente cuadro:

Tabla 3. Matriz Parcial Categoría Social.

\begin{tabular}{|c|c|c|}
\hline $\begin{array}{l}\text { Categoría social: derechos humanos, prácticas } \\
\text { laborales y participación activa y desarrollo de la } \\
\text { comunidad. }\end{array}$ & $\begin{array}{l}\text { Subtema } \\
\text { incorporado en } \\
\text { la legislación } \\
\text { colombiana }\end{array}$ & $\begin{array}{l}\text { Porcentaje } \\
\text { Asignado a } \\
\text { cada subtema }\end{array}$ \\
\hline Debida diligencia & No & $0 \%$ \\
\hline Situaciones de riesgo & No & $0 \%$ \\
\hline Complicidad & No & $0 \%$ \\
\hline Resolución de reclamaciones & No & $0 \%$ \\
\hline Discriminación y grupos vulnerables & Si & $1,25 \%$ \\
\hline Derechos civiles y políticos & Si & $1,25 \%$ \\
\hline Derechos económicos, sociales y culturales & Si & $1,25 \%$ \\
\hline Principios y derechos fundamentales en el trabajo & Si & $1,25 \%$ \\
\hline Trabajo y relaciones laborales & $\mathrm{Si}$ & $1,25 \%$ \\
\hline Condiciones de trabajo y protección social & Si & $1,25 \%$ \\
\hline Diálogo social & $\mathrm{Si}$ & $1,25 \%$ \\
\hline Salud y seguridad ocupacional & Si & $1,25 \%$ \\
\hline Desarrollo humano y formación en el lugar de trabajo & No & $0 \%$ \\
\hline Participación activa de la comunidad & No & $0 \%$ \\
\hline Educación y cultura & No & $0 \%$ \\
\hline Creación de empleo y desarrollo de habilidades & No & $0 \%$ \\
\hline Desarrollo y acceso a la tecnología & No & $0 \%$ \\
\hline Generación de riqueza e ingresos & No & $0 \%$ \\
\hline Salud & No & $0 \%$ \\
\hline
\end{tabular}




\begin{tabular}{|c|c|c|}
\hline Inversión social & No & $0 \%$ \\
\hline Total categoría social & - & $10 \%$ \\
\hline
\end{tabular}

Fuente: elaboración propia

Ponderación Categoría Ambiental: esta categoría es la más incorporada en la legislación colombiana, debido a que los cuatro subtemas tienen completa cobertura; desde la expedición del Código de los Recursos Naturales (Decreto Ley 2811 de 1974), comienza para Colombia una dinámica de creación de leyes en aspectos de protección ambiental, prevención de la contaminación y del uso sostenible de los recursos naturales, pero tiene su apogeo a partir de la entrada en vigencia de la Constitución de 1991, donde se da inicio a la protección del derecho colectivo al medio ambiente.

En efecto, en 1993 Colombia expide la ley marco (principal) sobre el medio ambiente, la Ley 99, que crea todo el Sistema Nacional Ambiental y el Ministerio del Medio Ambiente. Posteriormente, cuando se expide el Código Penal, Ley 599 de 2000 , se elevan a estatus de delitos los daños sobre el medio ambiente, la contaminación, el tráfico de fauna y flora, entre otros. Igualmente, se expiden otras leyes para proteger la biodiversidad, los recursos naturales de nuestros mares y ríos, los recursos mineros, el uso eficiente del agua, y de toda la fauna y flora colombiana. Con posterioridad a la expedición de la Ley 99 de 1993, se empieza a trabajar en la mitigación y adaptación al cambio climático y, en consecuencia, se expiden las Leyes 164 de 1994 y 629 de 2000, que enmarcan lo estipulado en la Convención de las Naciones Unidas sobre el Cambio Climático y el Protocolo de Kioto, respectivamente.

En ese marco se han implementado leyes como la 693 y 697 de 2001 que buscan disminuir la contaminación por el uso de hidrocarburos (que producen gases de efecto invernadero), y la Ley 1715 de 2014 que regula la integración de energías renovables no convencionales al sistema eléctrico nacional. Es por esta razón, que a los cuatro temas que tiene esta tercera categoría, se les asignó en la ponderación, la totalidad del porcentaje que se les puede otorgar, el 6,25\% para cada una de ellas, para un total de $25 \%$, como se puede observar en el siguiente cuadro: 
Tabla 4. Matriz Parcial Categoría Ambiental.

\begin{tabular}{|c|c|c|}
\hline Categoría ambiental: medio ambiente & $\begin{array}{c}\text { Subtema } \\
\text { incorporado en } \\
\text { la legislación } \\
\text { colombiana }\end{array}$ & $\begin{array}{c}\text { Porcentaje } \\
\text { Asignado a } \\
\text { cada subtema }\end{array}$ \\
\hline Prevención de la contaminación & $\mathrm{Si}$ & $6,25 \%$ \\
\hline Uso sostenible de los recursos & $\mathrm{Si}$ & $6,25 \%$ \\
\hline Mitigación y adaptación al cambio climático & $\mathrm{Si}$ & $6,25 \%$ \\
\hline $\begin{array}{c}\text { Protección del medio ambiente, la biodiversidad y } \\
\text { restauración de hábitats naturales }\end{array}$ & $\mathrm{Si}$ & $6,25 \%$ \\
\hline Total categoría ambiental & - & $25 \%$ \\
\hline
\end{tabular}

Fuente: elaboración propia

Ponderación Categoría Operacional: esta última categoría tiene una condición muy particular que la distingue de las otras tres, el resultado muestra que es más reciente (incluso la gran mayoría de leyes sancionadas son posteriores al año 2000) el desarrollo legal que incorpora los principios y temas de la ISO 26000 con relación con la lucha contra la corrupción, las reglas de competencia justa, el respeto de los derechos de los consumidores, y a los derechos de propiedad intelectual, el servicio al cliente, el consumo sostenible y la protección de los datos de los consumidores.

Todo lo anterior merece ser destacado porque Colombia, al entrar en el contexto mundial de los mercados, por medio de tratados de libre comercio, y más aún, con la meta que tiene de ser incluida en la $\mathrm{OCDE}^{6}$, está expidiendo una serie de leyes que busca hacer mucho más transparente y responsable el funcionamiento de su sector productivo. La Ley 1340 de 2009, que dicta normas en materia de protección de la competencia, el Estatuto Anticorrupción (Ley 1474 de 2011), el Estatuto del Consumidor (Ley 1480 de 2011), la Ley 1581 de 2012, donde se dictan medidas para la protección de los datos personales, y la Ley 1648 de 2013, por medio de la cual se establecen medidas para defender los derechos de propiedad industrial, son prueba de esto. Como corolario de lo anterior, se otorga un resultado para esta

6. Fundada en 1961, la Organización para la Cooperación y el Desarrollo Económicos (OCDE) agrupa a 34 países miembros, y su misión es promover políticas que mejoren el bienestar económico y social de las personas alrededor del mundo. La OCDE ofrece un foro donde los gobiernos puedan trabajar conjuntamente para compartir experiencias y buscar soluciones a los problemas comunes. Trabajan para entender qué es lo que conduce al cambio económico, social y ambiental. Se mide la productividad y los flujos globales del comercio e inversión. Analiza y compara datos para realizar pronósticos de tendencias. Fijan estándares internacionales dentro de un amplio rango de temas de políticas públicas. Para ver más visite: http://www.oecd.org/centrodemexico/laocde/ 
cuarta categoría, independientemente de si es una empresa privada o pública, de que tiene un nivel de incorporación en la legislación colombiana del 22,92\% de un total de $25 \%$, tal como se puede observar en el siguiente cuadro:

Tabla 5. Matriz Parcial Categoría Social.

\begin{tabular}{|c|c|c|}
\hline $\begin{array}{c}\text { Categoría operacional: Anticorrupción y } \\
\text { Consumidores }\end{array}$ & $\begin{array}{c}\text { Subtema } \\
\text { incorporado en } \\
\text { la legislación } \\
\text { colombiana } \\
\end{array}$ & $\begin{array}{c}\text { Porcentaje } \\
\text { Asignado a } \\
\text { cada subtema }\end{array}$ \\
\hline Anti corrupción & & $0 \%$ \\
\hline Participación política responsable & No & $0 \%$ \\
\hline Competencia justa & No & $0 \%$ \\
\hline $\begin{array}{l}\text { Promover la responsabilidad social en la cadena de } \\
\text { valor }\end{array}$ & No & $0 \%$ \\
\hline Respeto a los derechos de propiedad & $\mathrm{Si}$ & $1,25 \%$ \\
\hline Prácticas justas de marketing & $\mathrm{Si}$ & $1,25 \%$ \\
\hline $\begin{array}{c}\text { Protección de la salud y la seguridad de los } \\
\text { consumidores }\end{array}$ & $\mathrm{Si}$ & $1,25 \%$ \\
\hline Consumo sostenible. & $\mathrm{Si}$ & $1,25 \%$ \\
\hline $\begin{array}{c}\text { Servicio de atención al cliente, apoyo y resolución de } \\
\text { quejas y controversias }\end{array}$ & $\mathrm{Si}$ & $1,25 \%$ \\
\hline $\begin{array}{c}\text { Protección y privacidad de los datos de los } \\
\text { consumidores }\end{array}$ & $\mathrm{Si}$ & $1,25 \%$ \\
\hline Acceso a servicios esenciales & Si & $1,25 \%$ \\
\hline Educación y toma de conciencia & Si & $1,25 \%$ \\
\hline Total categoría operacional & No & $0 \%$ \\
\hline
\end{tabular}

Fuente: elaboración propia

Ponderación Total: en el siguiente cuadro se observa el resultado del nivel de incorporación de los principios y subtemas de la ISO 26000 en la legislación colombiana vigente para las organizaciones empresariales de bienes y servicios, anotando que durante el desarrollo de la investigación surgen las hipótesis de aplicación de la ley teniendo en cuenta la diferenciación de si la empresa es privada o pública: 
Tabla 6. Ponderación total.

\begin{tabular}{|c|c|}
\hline $\begin{array}{c}\text { Total nivel de incorporación principios y subtemas ISO } 26000 \text { en la } \\
\text { legislación colombiana vigente para organizaciones empresariales privadas } \\
\text { (máximo 100\%) }\end{array}$ & $58 \%$ \\
\hline $\begin{array}{c}\text { Total nivel de incorporación principios y subtemas ISO } 26000 \text { en la } \\
\text { legislación colombiana vigente para EICE's y EPS's públicas (máximo 100\%) }\end{array}$ & $83 \%$ \\
\hline
\end{tabular}

Fuente: elaboración propia

Luego de hacer una amplia revisión por las bases de datos legales gubernamentales de Colombia, se logró responder la pregunta de investigación que se planteaba en torno al nivel de incorporación de los principios y temas ISO 26000 en la legislación colombiana vigente para las organizaciones empresariales de bienes y servicios; pues, se estableció el nivel de incorporación de los principios y temas de la Norma Guía ISO 26000 en la legislación vigente para las organizaciones empresariales de bienes y servicios, identificando además una diferenciación para el cálculo de este nivel de incorporación; es decir, si la organización empresarial evaluada es de capital privado o de capital público, para la primera el nivel es del $58 \%$, valor que se considera es un nivel medio de obligatoriedad, lo que permite un $42 \%$ para que estas organizaciones privadas tomen la iniciativa voluntaria de aplicar postulados y acciones enmarcadas en lo que la ISO 26000 establece como RSE, especialmente en asuntos relacionados con inversión y apoyo a las comunidades en temas de salud, educación, creación de empleo, acceso a la tecnología, entre otros. Pero si es una organización empresarial con capital público, como una empresa industrial y comercial del Estado o una empresa de servicios públicos la evaluada, el nivel es del 83\%. Esta diferencia de un 25\% se explica mayormente, porque en esas organizaciones empresariales de capitales públicos, existe la obligación de gestionar procesos de planeación y de rendir cuentas de manera pública.

\section{Conclusiones}

Colombia tiene un marco legal amplio que cubre muchos aspectos incluidos en la ISO 26000, pero esto no debe ser considerado un obstáculo para poner en práctica los principios de la RSE, se debe mirar como un complemento, más cuando las leyes, por su carácter general, no logran cubrir todas las situaciones que se presentan en una sociedad; es por ello que los postulados de RSE cobran mucha importancia, especialmente en ciertos asuntos que son muy sensibles para la sociedad. Pero para lograr resultados en materia de RSE, se resalta en 
este trabajo que es más eficaz el educar, el incentivar y el motivar, que obligar o amenazar con sancionar a las personas sino siguen ciertos preceptos o cumplen con ciertas directrices. En términos teóricos (Carracedo, 1989; Lozano, 1999 y 2007), este punto zanja la discusión acerca de si la RSE es voluntaria (posconvencional) o si es obligatoria (convencional o preconvencional).

En Colombia, a juzgar por los resultados de este trabajo, la RSE se constituye en filosofía corporativa, en gestión ética libremente adoptada, justamente en ese margen de voluntariedad de $42 \%$ y de $17 \%$, según se trate de empresas privadas o de empresas de capital público, respectivamente. Y es obligatoria la RSE (de cumplimiento convencional) en virtud de que los temas y principios de la ISO 26000 son compatibles con los postulados del Estado Social de Derecho.

El Estado tiene la obligación Constitucional de velar por el bien de las personas en Colombia, defender los derechos consagrados en las leyes y siempre buscar el bien común. Por ello, hay defensores entre algunos dirigentes del gobierno y políticos en el Congreso colombiano, quienes manifiestan que toda la prestación de servicios públicos debe estar en manos del mismo Estado, y no en particulares, porque los segundos buscan el lucro, la ganancia como fin de su accionar empresarial. En cambio las organizaciones empresariales públicas deben tener como fin el maximizar los beneficios de las comunidades donde están asentadas. Entonces, si bien el interés general debe prevalecer por encima del particular de acuerdo con los postulados constitucionales, y en Colombia, como Estado Social de Derecho, deben garantizarse todos los derechos fundamentales a sus gobernados, el principio de Libertad de Empresa debe comprometer a dichas empresas privadas a que actúen conforme a los fines que tienen las empresas públicas, para que de esta manera, y apelando el derecho a la igualdad, pueda materializarse el postulado del artículo primero de la Carta Política Colombiana.

Resulta entonces afortunado, que la misma ley obligue a las empresas privadas que manejan capitales o dineros públicos, o aquellas que prestan un servicio público a actuar como si fueran completamente públicas y deban rendir cuentas, además de que muchas son vigiladas por los entes de control como la Contraloría, la Procuraduría, entre otras. Por tal razón, es que a pesar de que en este trabajo se observa una diferencia entre estas dos clases de empresas, $58 \%$ vs $83 \%$, en el caso de las empresas de servicios públicos privadas y las públicas no hay realmente una diferencia en la carga legislativa a cumplir, lo que sí sucede con las Empresas Industriales y Comerciales del Estado, EICE's, que están desarrollando alguna actividad que no es considerada un monopolio de Estado (tal es el caso de la producción de ciertos licores y armamento que solo lo hace el 
Estado), en esta situación, estas Empresas Comerciales del Estado compiten con empresas privadas, que no tienen que cumplir con leyes que cubren los subtemas contenidos en la primera categoría (gobernanza).

Al revisar la matriz obtenida en el presente trabajo se concluye entonces que los trabajadores y los consumidores son los stakeholders más protegidos legalmente en Colombia; los propietarios y directivos tienen ciertas cargas legislativas a cumplir, como lo es llevar registros que deben ser inscritos en las Cámaras de Comercio donde tienen su domicilio legal, rendir algunas cuentas, pero de manera privada, etcétera. Es muy incipiente la cobertura hacia los proveedores y toda la cadena de suministro, igualmente, para los distribuidores y comercializadores de los productos fabricados por esas empresas. Y siguiendo la clasificación hecha por Jaramillo Arango (2013), que establece tres ejes en la RSE, es el eje ambiental el más protegido por la legislación colombiana, seguido del eje social (énfasis en los derechos humanos, población vulnerable, trabajadores y consumidores). No existe cobertura en aspectos de inversión social en las comunidades. El eje económico tiene una cobertura incipiente enfocado a una rendición de cuentas limitada y privada.

Frente al último objetivo específico de este trabajo, se identificaron algunos vacíos legislativos en relación con aspectos contenidos en la ISO 26000. Si bien, el porcentaje de normas que se revisó en las bases de datos mencionadas en precedencia, es del noventa por ciento aproximadamente (90\%), pues como se dijo anteriormente, no se puede asegurar que está el 100\% de todas las leyes que incluyan alguno de los temas contenidos en la ISO 26000. Los vacíos más representativos encontrados están referidos a la rendición pública de cuentas de las organizaciones empresariales privadas, a la gestión de acciones encaminadas a la defensa de los derechos humanos de este tipo de organizaciones, y en la obligación de realizar acciones encaminadas a mejorar la calidad de vida de las comunidades, con las cuales estas organizaciones empresariales privadas tienen relación directa e indirecta, mediante el fomento a la educación, a la cultura, a la salud, el acceso a la tecnología, a la formación empresarial y laboral, y en general, en hacer inversión social.

Como ya se mencionó en el acápite de los resultados, se hace énfasis en la advertencia de que la persona que lea y pretenda hacer uso de la matriz, debe revisar en los portales gubernamentales y en los diferentes buscadores la vigencia de todas de estas leyes. Es en este punto que los legisladores colombianos deben hacer esfuerzos por promulgar leyes que estimulen la inversión social en las comunidades, que se realicen campañas desde los entes del gobierno 
para fomentar estas acciones, pero se debe tener cuidado en no generar más cargas a las empresas que desestimulen el funcionamiento de las mismas, o inclusive, las lleve a pensar en moverse a otros países (esto es más fácil para las multinacionales). Se debe investigar más en estos aspectos, y en cómo crear un equilibrio entre los fines que persiguen las empresas y el bienestar de las comunidades, en dejar de ser reactivos (multas y sanciones para las empresas cuando se ve afectada negativamente a la comunidad), y en buscar ser proactivos (estímulos e incentivos por generar bienestar en la comunidad).

Como cierre de este trabajo, queda un aspecto jurídico que genera un debate relacionado con el papel de las organizaciones empresariales en el contexto del Estado Social de Derecho en el cual Colombia está enmarcada. El Estado Social de Derecho va más allá del imperio de la ley que caracterizaba al Estado de Derecho; el aspecto social le genera una característica especial, donde se tutelan los derechos fundamentales de las personas y de los grupos sociales, es decir, que el Estado debe proteger todos esos derechos que son consagrados como fundamentales y esenciales para todos, y donde impera el interés general por encima del particular. Incluso, el derecho de propiedad pasa de ser un derecho absoluto a tener funciones sociales, verbigracia, los procesos de expropiación de propiedades a los particulares, en los casos de obras que benefician a toda la comunidad, debido a su utilidad social. Pero queda entre el tintero, la función o el papel de las empresas en todo esto, como ya se mencionó en este trabajo, las empresas hacen parte de este marco de Estado Social de Derecho, y son ellas las que tienen la obligación de buscar el bienestar de las comunidades, y de la sociedad en general. Se aclara, sin embargo, que aquí no se está hablando de una simple imposición normativa, es un fin mucho más grande y más loable, y es el de que las empresas comprendan que la sociedad gira en torno a la comunidad (todas las personas), que están ubicadas geográficamente, que tienen proveedores que hacen parte de ella, sus trabajadores, sus clientes, sus consumidores, etcétera; todos ellos son miembros de esa comunidad, y por ende, estas empresas deben pensar no solamente en alcanzar el máximo lucro legal posible, sino que además, deben buscar el mayor bienestar para todos sus stakeholders.

Es aquí donde cumplen un papel muy importante las leyes existentes que guardan relación con la RSE, ya que ellas actúan como herramienta de equilibrio en aquellos casos donde las empresas son entes aislados de la sociedad y sus comunidades, y en aquellas situaciones en las que incluso afectan de manera negativa a estas mismas. Sería ideal que las empresas no necesitaran de leyes o regulaciones para integrarse con la comunidad, y que se sumaran en esa búsqueda del mayor bienestar comunitario. Pero donde no se presenta esto, 
las leyes contribuirán a realizar esos postulados del Estado Social de Derecho; empero, la RSE puede hacer esto mismo sin tener que constreñir a las empresas, pues estas implementarían acciones de gestión empresarial en RSE que ayuden a alcanzar los postulados y los objetivo propuestos en el Estado Social de Derecho. Por ello, es importante resaltar lo que se dijo inicialmente sobre la Responsabilidad Social Empresarial, y es que ésta tiene una estrecha relación con los principios y valores de los Estados Sociales de Derecho, y que de hecho, tienen muchas coincidencias, tales como, los aspectos de la lucha por la defensa de los derechos humanos, los derechos de los trabajadores, los derechos de los niños, la defensa del medio ambiente, los derechos de las personas cuando actúan como consumidores, y el derecho a la propiedad, entre otros.

Hoy, todas las organizaciones empresariales tienen obligaciones sociales y colectivas; su objeto social, además de buscar el lucro, es el del deber respetar muchos lineamientos sociales y ambientales, ya no es el de obtener la mayor utilidad al modo que sea. Las empresas tienen una responsabilidad con la sociedad en la cual se encuentran ubicadas, incluso yendo más allá, un compromiso con todo el planeta, como se dijo en precedencia. De hecho, existe un órgano de control para que se respeten estos postulados inherentes al Estado Social de Derecho; en Colombia, la Corte Constitucional es el tribunal que defiende la aplicación de los derechos consagrados en la Constitución Colombiana, y de los principios y valores de este Estado Social de Derecho. Es por esto, que las leyes y las demás normas existentes deben respetar estos principios, y cuando no lo hacen, son declaradas inexequibles, siendo derogadas del ordenamiento jurídico por esta corte; en algunos casos, se hace de manera automática porque la misma Constitución así lo autoriza, y en otros, porque los ciudadanos las demandan ante esa misma corte por medio de la Acción de Inconstitucionalidad.

\section{Conclusiones}

Amaeshi, M. y Bongo, A. (2007) Reconstructing the corporate social responsibility construct in Utlish. Business Ethics: A European Review, 16(1), 1-18.

Baylos, A. (2013). Prologo en "La Responsabilidad Social Empresarial, base fundamental para el cumplimiento y fortalecimiento de los derechos laborales”. $1^{a}$ edición, p 11-17. Medellín: Biblioteca Jurídica Dike. 
Berbel, G. (2010). Aproximación y apreciaciones sobre la RSE en Europa. En: Responsabilidad Social Empresarial - Una reflexión desde la gestión, lo social y ambiental. $1^{\text {a }}$ edición, p 127-160. Bogotá: Universidad Nacional de Colombia sede Bogotá.

Carracedo, J. (1989). La Psicología Moral (de Piaget a Kohlberg). En: CAMPS, Victoria. Historia de la Ética (pp. 481-532). Tomo III. Barcelona: Crítica.

Carroll, B. (2001). The pyramid of corporate social responsibility: Toward the moral management of organizational stakeholders. Business Horizons. 3948.

Ciro, L. S. (2010). La responsabilidad social empresarial vista a la luz de Manizales: Universidad Autónoma de Manizales. intentos normativos. MBA-UA RM temas claves. 58-102. Colección ciencias sociales y humanas.

Gjølberg, M. (2011). Explaining regulatory preferences: CSR, soft law, or hard law? Insights from a survey of Nordic pioneers in CSR. Business and politics: 13(2), 4, 31. Berkeley Electronic Press.

Gómez, M. (2010). Evaluación crítica de un caso de responsabilidad social empresarial (RSE) en una empresa de cemento en Colombia. En: Responsabilidad Social Empresarial - Una reflexión desde la gestión, lo social y ambiental (pp. 201-228). $1^{\text {a }}$ edición, Bogotá: Universidad Nacional de Colombia sede Bogotá.

Herrera, B. (2010). Responsabilidad social empresarial y acceso de las empresas a la economía global. En: Responsabilidad Social Empresarial - Una reflexión desde la gestión, lo social y ambiental (pp. 47-92). 1ª edición, Bogotá: Universidad Nacional de Colombia sede Bogotá.

Infestas, Á. (2001). Sociología de la empresa. Salamanca, España: Amarú Ediciones.

International Organization for Standardization, ISO. (2011) ISO 26000. $1^{\mathrm{a}} \mathrm{ed}$. 132 p. Switzerland: International Organization for Standardization ISO Central Secretariat, 1, ch. de la Voie-Creuse, CP 56, CH-1211. Geneva 20.

Jaramillo, I. C. (2013). La Responsabilidad Social Empresarial, base fundamental para el cumplimiento y fortalecimiento de los derechos laborales. Medellín: Biblioteca Jurídica Dike. 
Lozano, J. M. (1999). Ética y Empresa. Madrid: Trotta.

Lozano, J. M., et al. (2007). Tras la RSE - la responsabilidad social de la empresa en España vista por sus actores. Barcelona: ESADE, instituto de innovación social.

Martínez, C. E. (2010). RSE y lineamientos de investigación desde la perspectiva de la teoría de la gestión. En: Responsabilidad Social Empresarial - Una reflexión desde la gestión, lo social y ambiental (pp. 1-45). Bogotá: Universidad Nacional de Colombia sede Bogotá.

Moreno, C. E. (2010). Aprendizaje organizacional y responsabilidad ambiental empresarial. En: Responsabilidad Social Empresarial - Una reflexión desde la gestión, lo social y ambiental (pp. 93-126). Bogotá: Universidad Nacional de Colombia sede Bogotá.

Rojas, A.L.y Olaya,J.E.(2012). Responsabilidad socialempresarial:suorigen, evolución $y$ desarrollo en Colombia. Universidad Santiago de Cali. 12p. Recuperado de: http://redunirse.org/nuevo/sites/default/files/pdf/Responsabilidad\%20 Social\%20Empresarial\%20su\%20origen,\%20evoluci\%C3\%B3n\%20y\%20 desarrollo\%20en\%20Colombia.pdf

Tricot-Chamard, I. y Estay, C. (2011). Quand la responsabilité juridique vient enrichir la responsabilité sociales des entreprises. En: Gestión 2000 (pp. 83-100). Septiembre - Octubre.

Villa, L. E. (2011). Tres enfoques éticos determinantes para la Responsabilidad Social Empresarial. En: Capitalismo y empresa: reflexiones desde la ética y la RSE (pp. 69-93). Bogotá: Edit. Pontificia Universidad Javeriana.

Yepes, G. A., et al. (2007). Responsabilidad social empresarial - fundamentos y aplicación en las organizaciones de hoy. Bogotá: Universidad Externado de Colombia. 